\title{
The dualistic model of passion in adapted sport: a double-serial mediation analysis on satisfaction with life
}

\author{
Diogo S. Teixeira ${ }^{1,2}$ (1) - Filipe Rodrigues ${ }^{3,4}$ - Anabela Vitorino ${ }^{3,5} \cdot$ Luís Cid $^{3,5} \cdot$ Teresa Bento $^{3,5}$. \\ Anastasiia Evmenenko ${ }^{1} \cdot$ Rita Macedo ${ }^{6} \cdot$ Verónica Morales-Sánchez ${ }^{4} \cdot$ Diogo Monteiro $^{4,5}$
}

Accepted: 2 August 2021

(C) The Author(s), under exclusive licence to Springer Science+Business Media, LLC, part of Springer Nature 2021

\begin{abstract}
Adapted sports practice has increased in recent years, and has now put an additional demand on research to further explore and understand the characteristics of this field of practice. The main aim of this study was to examine the serial mediation effects of motivation and affective activation in relationships between passion and satisfaction with life in adapted sports athletes. The study sample comprised 143 adapted sports athletes (male $=107)$ aged between 15 and 59 years $(M=29.21 ; S D=10.45)$ enrolled in distinct modalities. Double serial mediation models were developed according to hypothetical associations, and were analyzed using PROCESS macro v. 3.3. In both models, no direct effect between the types of passion and satisfaction with life emerged. However, positive indirect effects through self-determined motivation have emerged in the harmonious and obsessive passion models, as for a distinct and positive effect of relatedness in satisfaction with life.
\end{abstract}

Keywords Harmonious passion $\cdot$ Obsessive passion $\cdot$ Motivation $\cdot$ Well-being $\cdot$ Life Satisfaction $\cdot$ Adapted sports

\section{Introduction}

High performance sport provides opportunities for people with disabilities to develop their skills and fulfill their potential, experience enjoyment and pleasure, success, and overcome their limits (DePauw \& Gavron, 2005). Despite the fact that opportunities for practice for people with disabilities are still limited when compared to sport in general (Lundberg et al., 2010), the number of adapted sport athletes has increased considerably in recent years (IPC, 2015). Consequently, literature on adapted sport is still scarce

\section{Diogo S. Teixeira}

diogo.teixeira@ulusofona.pt

Lusófona University (FEFD/ULHT), Lisbon, Portugal

2 Research Center in Sport, Physical Education, and Exercise and Health (CIDEFES), Lisbon, Portugal

3 Life Quality Research Center (CIEQV), Santarém, Portugal

4 ESECS, Polytechnique of Leiria, Leiria, Portugal

5 Research Center in Sport Sciences, Health and Human Development (CIDESD), Vila Real, Portugal

6 Center for Organizational and Social Studies of P. PORTO, (CEOS.PP P. PORTO), Porto, Portugal compared to sport in general, and further research is crucial to better understand these contexts and athletes (Martin, 2018).

Some of the existing literature on the adapted sport context has covered the interdynamics of motivational processes as a way to better understand their relation with persistence, performance, well-being, and other psychological processes (e.g., Banack et al., 2011; Heo et al., 2008; Lundberg et al., 2010). In particular, the Self-Determination Theory (SDT) framework, developed by Deci and Ryan (1985), has been used to explore the role of motivational aspects in general sports as well as in adapted sports (e.g., Lightheart et al., 2010; Heo et al., 2008; Perreault \& Vallerand, 2007).

For the past decades, the understanding of internalization and integration processes proposed by SDT has been expanded with the contributions made by Vallerand et al. (2003) and the Dualistic Model of Passion (DMP). In several studies, it is proposed that the type of passion an athlete experiences in his practice can have implications for sport commitment, behavioral regulation, interpersonal relationship, well-being, among others. These findings might be of particular relevance for athletes and coaches (Parastatidou et al., 2014; Rip et al., 2006; Schiphof-Godart \& Hettinga, 2017; Vallerand et al., 2008). Given the myriad of additional outcomes, these interactions warrant further exploration, especially in the adapted sports context, where the general patterns 
of practices and athletes' characteristics are not yet adequately understood. Thus, considering the specific adapted sports context, it becomes important to understand how the type of passion experienced could be related with i) the motivational quality associated to practice, and ii) subjective well-being.

\section{Dualistic Model of Passion}

According to Vallerand et al. (2006, Vallerand et al., 2007), passion reflects a strong inclination and desire to engage in an activity that is considered important or appreciated by an individual. It can be considered to be more than "love" for an activity and can drive individuals to behave in a specific way, determining how they will dedicate themselves to a certain activity, experience pleasure, and persist in a given behavior (Vallerand \& Verner-Filion, 2020). This conceptualization was the foundation for the development of the Dualistic Model of Passion, which postulates the existence of two types of passion, Harmonious Passion (HP) and Obsessive Passion (OP). These types of passion reflect not only the love for the activity, but also the value of the activity that can be distinguished by an the extent to which a behavior is integrated into the person's self (Vallerand et al., 2003; Vallerand \& VernerFilion, 2020).

HP is associated with autonomous internalization. In sport context, for example, athletes practice sport willingly and with a sense of volition, and mainly because of the pleasure derived from the activity, without striving for strengthening their personal identity. In other words, the activity does not control the individual, since it is a personal desire to practice it without experiencing feelings of obligation or internal pressure. Thus, athletes feeling HP regarding their sport practice can better manage the time spent on the activity without experiencing internal conflicts with other daily tasks (i.e., all activities are compatible within his personal schedule). For instance, the following statement - "This sport shows the qualities that I like most about myself", represents an athlete experiencing HP (Vallerand et al., 2003).

OP is associated with controlling internalization in which athletes force themselves to practice sport, therefore seeking feelings of social acceptance or increased self-esteem, and experiencing internal pressure to engage in sport. In this type of passion, sport practice may be related to achieving public affirmation reinforcing athlete's own identity, thus feeling dependence when abstinent from the practice. In this regard, athletes engaging in sport for OP reasons have difficulties managing their time between sport and daily activities (i.e., there is no congruence between the activities). For example, an athlete stating "The need is so strong that I cannot stop practicing this sport", is representative of OP (Vallerand et al., 2003). Thus, both types of passion are integrated within the individual's self, but OP seems to occupy an overwhelming space in their identity. Specifically, the individual feels compelled to engage in the activity due to ego-involvement and internal contingencies of self-worth, albeit loving the activity. Contrarily, in the case of HP, harmoniously passionate activities, being equally important, occupy a balanced and not disproportionate space in the identity of the individual (Hodgins \& Knee, 2002; Mageau et al., 2011).

According to several studies, the HP and OP are in general moderately correlated. This assumption is aligned with the DMP framework and may have differentiated behavioral, cognitive, and affective outcomes (Vallerand, 2015). Thus, it seems that HP can facilitate performance attainment in sport, leading to better indexes of self-determined motivation and well-being. In some studies, HP has been reported to be associated with positive affect, vitality, and cognitive-emotional engagement for in-task activities (Curran et al., 2015). HP has also been associated with higher life satisfaction and lower life conflict outside the activity (Curran et al., 2015; Vallerand, 2015). Previous literature has associated HP with less negative affect, burnout, and ruminative cognition (Curran, Appleton, Hill, \& Hall, 2013; Curran et al., 2015; Kent et al., 2018). As for OP, positive associations are manifested with both well-being and ill-being indicators (e.g., positive and negative affect), but are in general smaller in magnitude when compared with HP (Curran et al., 2015; Vallerand et al., 2008). Unlike HP, OP has a deleterious effect on several well-being indicators (in- and outside-task) due to the need to maintain negative affect, non-integrated motivation, and compulsive engagement (Curran et al., 2015).

\section{Self-Determination Theory}

Among existing theories on motivation and behavior, SelfDetermination Theory (SDT; Ryan \& Deci, 2017) stands out as one of the most contemporary frameworks used in the physical activity domain, providing a clear understanding of the motivational factors responsible for several emotional, cognitive, and behavioral outcomes (Warburton et al., 2020; Rodrigues et al., 2020). SDT addresses human motivation in a broader perspective considering personality and social factors, as well as the causes and consequences of self-determined behavior (Deci \& Ryan, 2000).

According to Ryan and Deci (2017), motivation is influenced by the extent to which three Basic Psychological Needs (BPN) are satisfied. The motivation towards a given behavior is contingent to the fulfillment of the need for autonomy (i.e., feeling of volitional choices), for competence (i.e., feeling skillful and mastering new abilities), and for relatedness (i.e., feeling connected with others and experiencing positive social bonds). In accordance with this postulate, several studies have demonstrated the usefulness of understanding the motivational processes in the sports context, suggesting that the satisfaction of these needs is positively associated with selfdetermined motivation and negatively associated with 
nonself-determined motivation (Monteiro et al., 2019; Rodrigues et al., 2020; Monteiro et al., 2018; Sarrazin et al., 2007; Teixeira et al., 2019).

Contrary to the dichotomy between intrinsic and extrinsic motivational approach, SDT proposes a motivational continuum ranging from the absence of will to act or lack of intention to behave (i.e., amotivation), to behaving in order to get the pleasure and enjoyment that is inherent to the behavior (i.e., intrinsic motivation). In between, the continuum displays different regulations from the most controlled forms of motivation up to more autonomous forms of motivation. Performing certain behavior so as to obtain rewards and/or to avoid punishment (i.e., external regulation), or imposing self-pressures to perform the behavior to avoid negative feelings such as guilt and anxiety (i.e., introjected regulation), are related to the controlled forms of motivation. The more autonomous forms of motivation are associated with the individual that accepts the behavior and identifies it as valuable, although he may not totally like it (i.e., identified regulation), or with the individual that may integrate the behavior to their identity, with a high degree of harmony/congruence with other values and needs (i.e., integrated regulation).

Research in the sport context has shown autonomous motivation to be a significant predictor of positive cognitive outcomes, such as intentions to maintain sport practice (Monteiro et al., 2018), and affective outcomes (Gagné \& Blanchard, 2007). Contrarily, controlled motivation appears to be associated with negative outcomes such as burnout (Bartholomew et al., 2011) and presents a negative association with wellbeing (Carpentier \& Mageau, 2013; Jowett et al., 2017).

\section{Integrating the Dualistic Model of Passion and Self-Determination Theory}

As mentioned previously, SDT examines personal and contextual factors related to the individuals' personal growth and development. As for passion (according to the DMP), it is described as a strong inclination and desire towards an activity individually defined as important or appreciated. Thus, the two conceptualized forms of passion may be seen as a result of internalization processes, where HP reflects an aspect of one's identity that has been internalized in an autonomous fashion and are a constituent of the self, and OP emanates from a controlled internalization of the activity into one's identity in a specific context, as is the case of sport (Vallerand et al., 2006).

This autonomous internalization develops when an individual accepts the activity as important for them without external contingencies, which is related to the intrinsic and integrative tendencies of the self, as postulated by the SDT. For that matter, individuals experiencing HP are expected to engage in activities willingly and fully focused, and experience positive outcomes during engagement in the activity (e.g., positive affect, life satisfaction, flow), as stated in previous studies (Vallerand et al., 2006; Vallerand, 2015). In contrast, obsessive passionate individuals tend to perceive the activity as being partially or even completely outside the integrating self, increasing the risk of experience conflicts and other negative affective, cognitive, and behavioral consequences during and after the engagement in the activity (Vallerand et al., 2006). Therefore, HP is supposed to be more strongly associated with adaptive outcomes than OP, and may influence differently the passion towards an activity.

However, HP and OP, although expressing a love for an activity, have different expressions in the individual identity. For instance, HP occupies an important but adjusted space in personal identity, engaging the passionate activity freely, mindfully and in a non-defensive manner. This ensures an authentic integration in the self, allowing the person to fully partake in the passionate activity with an openness that is conducive to positive experiences (Vallerand et al., 2006; Mageau et al., 2011). That is not the case for OP, which may occupy an overwhelming space in one's identity, reflecting ego-involvement, and having self-worth contingencies attached. This may foster the OP to be partially internalized in the self, possibly causing an activity dependence, frustration, rumination and general suboptimal functioning (Vallerand et al., 2006).

Taking into account the DMP and motivational regulation dynamics, previous research has shown HP to be positively related to autonomous forms of motivation in the passionate activity. Conversely, OP has shown mixed results, showing that positive association may emerge with integrated and nonintegrated forms of motivation. Additionally, OP associations with integrated motivation have been reported to be generally lower that those obtained with HP (Curran et al., 2015; Vallerand et al., 2008). This distinction is relevant due to the more adaptive pattern of behavior engagement and motivation promoted by HP, thus ensuring a positive influence on volitional practice, performance and well-being that cannot be fully achieved with OP (Curran et al., 2015).

A component that is considered essential to sport engagement is the fulfillment of needs. It is postulated that social environment may facilitate these needs satisfaction, contributing to an overall improvement of behavioral regulations, which will allow for a healthier engagement in sports (Ryan \& Deci, 2017). Additionally, BPN assumptions may offer a conceptual basis to describe how passion may influence the satisfaction of psychological needs, and it has been conceptualized that it can either satisfy or thwart these needs (Forrest et al., 2011; Lalande et al., 2017; Houlfort et al., 2015). Due to the flexible and volitional characteristics of HP, because of the non-controlling nature of it, this manifestation of passion may serve as an essential component for BPN satisfaction. As for $\mathrm{OP}$, due to its somewhat rigid and controlled characteristics, a few bases for need thwarting may be present (Deci \& Ryan, 
2000; Houlfort et al., 2015). Moreover, a recent review supports this assumption reinforcing the importance of the passion-needs dyad in regulatory processes in behavioral regulations (Curran et al., 2015). This review showed that harmoniously passionate individuals presented higher levels of positive emotions (e.g., positive affect), volition (indicator of autonomous behavior), and greater sense of life satisfaction. Conversely, the more obsessively passionate individuals showed less desirable and maladaptive consequences (e.g., negative affects, BPN, intrinsic motivation).

In sum, the DMP assumptions seem to be intrinsically connected with key aspects of SDT, given that an activity that satisfies one's needs tends to increase its value, facilitate a more autonomous behavioral regulation, and promote a more adjusted and healthy engagement.

\section{Motivation and Well-Being in Sport}

Subjective well-being is a multidimensional construct related to one's identification of factors that contribute to subjective perceptions of personal equilibrium, health, and development, which have been defined as a positive dimension of health in the past decades (Seaward, 2000). According to Diener (1984, 1994), subjective well-being is characterized by the presence of positive aspects, the absence of negatives ones, as well as by a positive perception of satisfaction with one's life.

This construct comprises affective and cognitive dimensions. The affective dimension is defined by the positive and negative affects experienced, representing how each individual manifests these feelings, and how positive affects can be dominant over negative ones (Diener, 1994). The cognitive part is related to life satisfaction, which corresponds to the person's assessment at each moment of their life (Diener, 1985). It is influenced by a comparison between the current circumstances and what the individual defines as an appropriate standard, and therefore, it is not externally imposed (Diener et al., 1985; Pavot \& Diener, 2008).

In the sport context, the concept of subjective well-being has triggered considerable interest among researchers (Carpentier \& Mageau, 2013; Felton \& Jowett, 2013), extending its influence to the adapted sport environments (Macdougall et al., 2015). This conceptualization has been further explored, and the dynamics of the subjective wellbeing constructs (life satisfaction, positive affect and negative affect) show a reasonably expected interaction among them (Busseri \& Sadava, 2010). For this matter, levels of affective activation may act as predictors of life satisfaction and, consequently, subjective well-being (Busseri \& Sadava, 2010; Ekkekakis, 2013; Watson et al., 1999), and may, therefore, act as mediators in these relationships (Vallerand \& VernerFilion, 2020).

Moreover, several studies have explored the relation between motivation and subjective well-being constructs.
Regarding SDT based studies, it is well supported that BPN satisfaction and autonomous regulations are positively associated with positive affects, enjoyment, life satisfaction in various types of physical activity (Ryan \& Deci, 2017; Teixeira, Marques, \& Palmeira 2018) and in sport related contexts (Balanguer et al., 2008; Nunez et al., 2011; Teixeira et al., 2019; Monteiro, Pelletier, et al., 2018; Gillet et al., 2013). Additionally, the study conducted by Lalande et al. (2017), and particularly the review presented by Curran et al. (2015), supported some positive associations of HP in several cognitive, behavioral, and emotional outcomes (e.g., positive affect, life satisfaction), and some negative or trivial associations of OP with subjective well-being related variables.

\section{The Present Study}

Considering previous works, it is possible to hypothesize that distinct levels of passion may influence behavioral regulation, partially determining a wide array of well-being outcomes. In general, and in non-adapted sports populations, the associations between behavioral regulation (both autonomous and controlled) $>$ cognitive/emotional/behavioral consequences and their mediation role seems quite clear (Monteiro et al., 2018; Monteiro, Teixeira, et al., 2018; Teixeira et al., 2019).

However, neither the passion constructs proposed by the DMP, nor the motivational sequence hereby proposed, have been examined in adapted athletes in the sport context, further reinforcing the need to an additional look in these possible variables interaction. In fact, Vallerand and Verner-Filion (2020) reported that positive emotions can have a mediating effect between passion and psychological well-being, particularly triggered by harmonious passion. Additionally, the authors also suggest that "passion on well-being can go beyond the passionate activity as it may also affect satisfaction in other life domains" (p. 212), which support current study hypothesis.

Moreover, considering the multidimensional aspect of subjective well-being, two additional relevant issues arise: i) how may regular sport practice of these athletes help overcome some daily life limiting factors of well-being development, and ii) how could coaches and sport agents extrapolate the current knowledge of DMP and SDT factors onto the peculiarities of the adapted sports reality, in order to improve sport persistence and positive well-being among athletes with disabilities.

This study proposes that the serial mediation model takes into account the aforementioned motivation considerations, establishing passion as a 'background' that has an influence on motivational determinants, which in turn will be related with levels of positive and negative affective activation and, consequently, related with life satisfaction perceptions. Because the independent and collective indirect effects of the variables are of interest, serial mediation model testing will 
allow the understanding of the role of each variable independently and, sequentially, provide a better understanding of the most relevant factors in this context.

Thus, the present study could help address and add to an understanding of how passion experienced by athletes could be associated with the motivation for the sport activity and individual's subjective well-being. Considering the aforementioned theoretical background and existing evidence, is stands as particularly relevant to understand how the specific nature of adapted sports practice and athletes could influence this variables interactions. Given this rationale, the proposed models hypothesize that i) harmonious passion will be positively associated with subjective well-being (both cognitive and affective components) (Curran et al., 2015), ii) obsessive passion will present less relevant associations with subjective well-being when compared with harmonious passion (Curran et al., 2015; Valerand et al., 2006), iii) both types of passion will be associated with a better motivational quality (albeit favoring harmonious passion contribution) (Mageau et al., 2011; Vallerand et al., 2006; Vallerand, 2015), and finally, that iv) behavioral regulations and affective activation will present significant indirect effects in the passion and satisfaction with life associations (Vallerand, 2015; Vallerand \& Verner-Filion, 2020).

Considering the presented hypotheses, the main aim of this study is to assess the serial mediation effects of motivation and affective activation in the relation between both types of passion and satisfaction with life in adapted athletes.

\section{Method}

\section{Participants}

For this study, a non-probability sampling method was used, and 143 adapted sport athletes (female $=36$; male $=107$ ) aged between 15 and 59 years $(M=29.21 ; S D=10.45)$ voluntarily engaged in this study. The athletes were engaged in different adapted sports, namely: wheelchair handball; athletics; wheelchair basketball; boccia; canoeing; cycling; horse riding; football 7-a-side; goalball; judo; Greco-Roman wrestling; swimming; precision orientation; tricycle; and rowing. Weekly training frequency ranged from 1 to 12 sessions $(M=4.52$; $S D=2.71)$ and competitive experience ranged from 1 to 28 years $(M=5.55 ; S D=6.98)$.

To be included, potential participants had to be registered athletes in the International Paralympic Committee (IPC) and have a national or international formal competitive sport practice over the last 6 months. In the current sample, athletes had international competition experience in the Paralympics and Deaflympics Games, World and/or European Championships, under the aegis of the IPC, International Committee of Sports for the Deaf (ICSD), the Portuguese Paralympic Committee
(CPP), and the respective international federations in the field of disabilities and sport. Overall, participants presented motor, sensory (visual and hearing), and/or cerebral paralysis disabilities.

\section{Instruments}

The Passion Scale (Portuguese version) (PSp: Cid et al., 2019) was used to evaluate the passion the athletes felt regarding their sport participation. The stem "think of an activity that you enjoy very much and spend a significant amount of time on" preceded the measurement, and participants were asked to indicate the level of agreement with each item. The scale consists of eight items (four per factor) to which participants responded on a seven-point scale ranging from 1 ("totally disagree") to 7 ("totally agree"). The items are grouped into two factors, representing HP (Cronbach's alpha = .75) (e.g., "I am completely taken with this activity") and OP (Cronbach's alpha = .90) (e.g., "I have difficulty imagining my life without this activity"), as stated by the DMP (Vallerand et al., 2003). In the Portuguese scale ( 8 items), in contrast with the original English version (14 items; Vallerand et al., 2003), 6 items were eliminated (HP: items 4, 5 and 6; OP: items 12, 13, and 14). Methodological justifications for this adjustment can be found in the study conducted by Cid et al. (2019).

The Behavioral Regulation Sport Questionnaire (Portuguese version) (BRSQ; Monteiro et al., 2019) was used to measure how athletes regulate their motivation towards sports. Participants were asked to classify several sentences based on how they regulate their behavior towards sport practice. Responses were given to 24 items (six per factor) rated on a seven point Likert scale ranging from 1 ("not true of me") to 7 ("completely true of me"), corresponding to the six types of motivation inherent to the motivational continuum (Deci \& Ryan, 2000): amotivation: (e.g., "but I question why I continue"), external regulation (e.g., "to satisfy people who want me to play"); introjected regulation (e.g., "because I would feel guilty if I quit"); identified regulation (e.g., "because I value the benefits of my sport"), integrated regulation (e.g., "because it's a part of who I am") and intrinsic motivation (e.g., "because I enjoy it"). For the purpose of the study, two constructs were created following several authors recommendations (e.g., Pelletier \& Sarrazin, 2007). Thus, two composite variables (self-determined motivation and non selfdetermined motivation) were created based on the ponderation value of each indicator on the latent factor. Internal consistency considering Cronbach's alpha coefficients in this sample ranged between .71 (amotivation) and .86 (identified regulation).

The Portuguese version of the Positive and Negative Affect Schedule) (PANAS; Galinha et al., 2014) was used to measure affective activation. The stem asked the participants to indicate the extent to which they felt certain feelings and emotions 
(e.g., interested; angry) in the last weeks. This scale comprises 10 items rated on a five-point Likert scale ranging between 1 ("none or very slightly") and 5 ("extremely"). The items are then grouped into two factors that represent the degree of positive affect (Cronbach's alpha $=.87$, item examples: "interested", "strong", "enthusiastic") and negative affect (Cronbach's alpha $=.83$, item examples: "perturbed", "scared", "angry"), based on Diener's (1985) hedonic perspective. Considering posterior amendments and clarification related to the original instrument (Watson et al., 1988), by the authors of the original scale (Watson et al., 1999) and other recommendations (Feldman, Barret \& Russel, 1998; Ekkekakis, 2013), the items in the PANAS measure were labelled as positive and negative activations. This was done to better represent something other than pleasure/displeasure and define constructs only by their arousal poles.

The Portuguese version of the Satisfaction with Life Scale (SWLS: Neto, 1993) was used to measure global cognitive judgement of athlete's life satisfaction. The stem asked participants to indicate to what extent they agreed with each of the five statements within the measure. Answers were scored using a seven-point scale anchored from 1 ("strongly disagree") to 7 ("strongly agree"). The items were then grouped into one factor defined as satisfaction with life (Cronbach's alpha $=.82$ ), which reflects the cognitive perspective of Diener et al. (1985).

\section{Procedures}

Before data collection, ethical approval was obtained from the ethical committee of the Research Centre in Sports Sciences, Health Sciences and Human Development (CIDESD; reference number: UID/DTP/ 04045/2019). Afterwards, potential participants were contacted at the training site (74\%), internship (14\%) or in specific situations during their competitions $(12 \%)$. The surveys were presented with a cover sheet explaining the purpose of the study. The authors, collaborators, and partnerships identifications were also presented to the participants. Athletes were provided with an anonymous survey to complete either by themselves, or assisted by the trainer, family member, or researcher if needed. In these circumstances, confidentiality and the need to provide information or make interpretations that wouldn't lead to biased responses were reinforced.

All procedures were completed in accordance with the ethical standards of the institutional research committee and with the Helsinki declaration and its later amendments or comparable ethical standards. Informed consent was individually obtained from all participants included in the study. The time to fill surveys ranged from 15 to $45 \mathrm{~min}$.

\section{Statistical Analysis}

Data were initially screened for missing values and normality. Descriptive statistics and bivariate correlations were calculated using IBM SPSS STATISTICS v.23. Data was imputed in participants with missing values $>5 \%$ using the Multiple Imputation approach (Allison, 2000). Multicollinearity diagnoses through tolerance and variance inflation factor (VIF) were performed as proposed by Hair et al. (2019), considering scores $\leq 10$ as acceptable.

For hypothesis testing, multiple mediation procedures were developed using IBM SPSS macro PROCESS v.3.3 and according to Hayes (2018) suggestions. Two double serial mediation models (i.e., model 82) were used to analyze mediation paths (one with HP and the other with the OP as the only independent variables). The upper side of the serial model consists of the 'positive' psychological variables (self-determined motivation [SDM] and positive activation), and the lower section of the 'negative' psychological sequence (non self-determined motivation [NSDM] and negative activation). A serial mediation process allows the estimation of direct, indirect (for the independent variable and each mediator individually, as for all the interactions in the proposed series), and total indirect effects. Considering the theoretical assumption that HP and OP are moderately correlated, we followed Hayes' (2018) recommendations and in each model we used the non-represented type of passion as covariate, allowing the estimation of the model considering the association between both types of passion. A bootstrap with 5000 samples was imputed and the Confidence Interval of 95\% CI was considered as proposed by several authors. Additionally, if the CI does not include zero, then a significant effect could be accepted (Preacher \& Hayes, 2008; Shrout \& Bolger, 2002).

\section{Results}

\section{Preliminary Analysis}

In Table 1 there are displayed the results of the descriptive statistics and bivariate correlations. The results revealed that the participants showed higher values of HP compared to OP, as well as higher scores of self-determined motivation compared to non self-determined motivation. Similar patterns appeared in positive activation compared to negative activation. Regarding normal distribution, no univariate outliers were observed. The results showed that both the tolerance and VIF test scores were above 0.1 and below 10 , respectively, ensuring the appropriate conditions to test the regression model.

Regarding bivariate correlations, HP and OP were positively correlated with self-determined motivation and positive activation. Self-determined motivation was positively correlated with positive activation and satisfaction with life, whereas 
Table 1 Descriptive statistics and bivariate correlations

\begin{tabular}{llllllll}
\hline & HP & OP & SDM & NSDM & SWL & PA & NA \\
\hline HP & $\mathbf{1}$ & $.55^{*}$ & $.52^{* *}$ & $-.26^{* *}$ & $.35^{* *}$ & $.45^{* *}$ & .02 \\
OP & - & $\mathbf{1}$ & $.48^{* *}$ & -.09 & $.33^{* *}$ & $.42^{* *}$ & .09 \\
SDM & - & - & $\mathbf{1}$ & -.04 & $.41^{* *}$ & $.51^{* *}$ & .11 \\
NSDM & - & - & - & $\mathbf{1}$ & -.01 & $-.24 * *$ & $.47 * *$ \\
SWL & - & - & - & - & $\mathbf{1}$ & $.25^{* *}$ & .01 \\
PA & - & - & - & - & - & $\mathbf{1}$ & -.09 \\
NA & - & - & - & - & - & - & $\mathbf{1}$ \\
Mean & 6.19 & 5.05 & 5.64 & 2.61 & 5.20 & 4.02 & 1.70 \\
SD & .70 & 1.32 & .80 & 1.27 & .98 & .59 & .67 \\
Range & $4-7$ & $1-7$ & $3-7$ & $1-7$ & $3-7$ & $3-5$ & $1-5$ \\
\hline
\end{tabular}

Note. $\mathrm{HP}=$ Harmonious Passion; $\mathrm{OP}=$ Obsessive Passion; $\mathrm{SDM}=$ SelfDetermined Motivation; NSDM $=$ Non-Self-Determined motivation; $\mathrm{SWL}=$ Satisfaction with Life $\mathrm{PA}=$ Positive Activation; NA = Negative Activation

non-self-determined motivation was positively correlated with negative activation and negatively correlated with positive activation. Lastly, satisfaction with life displayed a positive association with positive activation and no association with negative activation.

In Figs. 1 and 2 are shown the results from the serial mediation models analyses. It is possible to observe that in both models the total effects were positive and significant (HP model: $\beta=.32[.08, .38]$; OP model: $\beta=.17[.04, .32])$. No significant direct effect was detected in either models and only in the OP model the indirect total effect was significant $(\beta=.06[.01, .13])$.

The sequential indirect path from $\mathrm{HP} \rightarrow \mathrm{SDM} \rightarrow$ positive activation in the HP model presented positive and significant scores from HP to SDM, and consequently from SDM to positive activation. On the other hand, the sequential indirect path of $\mathrm{HP} \rightarrow \mathrm{NSDM} \rightarrow$ negative activation presented a negative and significant score from HP to NSDM, and a positive and significant score from NSDM to negative activation. SDM was the only variable that presented a significant effect on satisfaction with life $(\beta=.30[.08, .54])$.

The OP model presented a similar trend for the 'positive' psychological variables (i.e., all positive and significant), and in the 'negative' side only a positive and significant score of NSDM to negative activation. An additional significant regression emerged in this model between OP and negative activation $(\beta=.08[.01, .16])$. This model displayed similar patterns of the relations of SDM on satisfaction with life $(\beta=.30[.05, .54])$ as in the HP model.

\section{Discussion}

Considering previous theoretical assumptions and empirical research, the main aim of this study was to examine the serial mediation effects of motivation and affective activation in the relationships between both types of passion and satisfaction with life in adapted sport athletes.

Athletes with disabilities present unique characteristics that may reflect the need for different approaches regarding the relation between adapted sport participation and well-being. Bearing this in mind, the relationships among passion, motivational determinants, affective activation, and satisfaction with life warrant further understanding in order to avoid an oversimplistic generalization drawn from other contexts, backgrounds, and individuals (Martin, 2018). Considered as a whole, our findings highlight that athletes with disabilities are a group of individuals that considers sport as an expression of themselves, with their sport practice being determined by their passions. Moreover, current findings evidence the unique associations between passion types, motivation, affective
Fig. 1 Double Serial mediation model for Harmonious Passion, Motivational Regulations, Positive and Negative Activation and Satisfaction with Life. Note. Significant effect $\longrightarrow$, nonsignificant effect $-\rightarrow$; SDM Self Determined Motivation, NSDM - Non Self-Determined Motivation

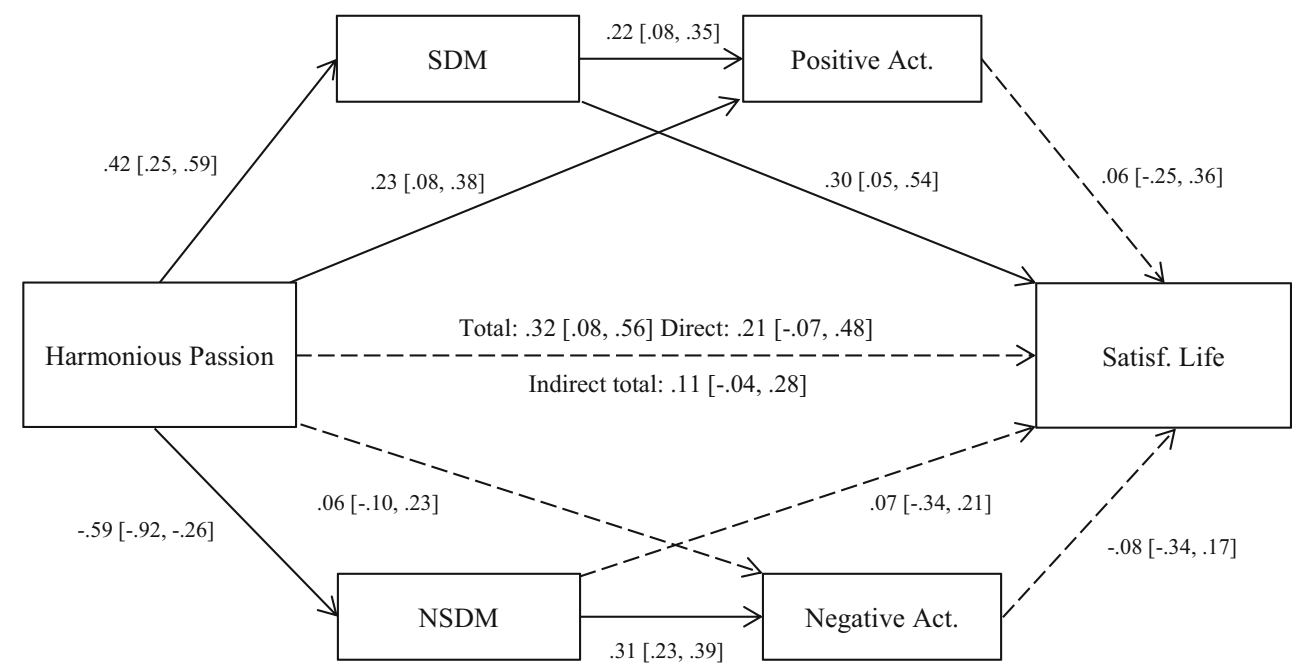


Fig. 2 Double Serial mediation model for Obsessive Passion, Motivational Regulations, Positive and Negative Activation and Satisfaction with Life. Note. Significant effect $\longrightarrow$, nonsignificant effect $--\rightarrow$; SDM Self Determined Motivation, NSDM - Non Self-Determined Motivation

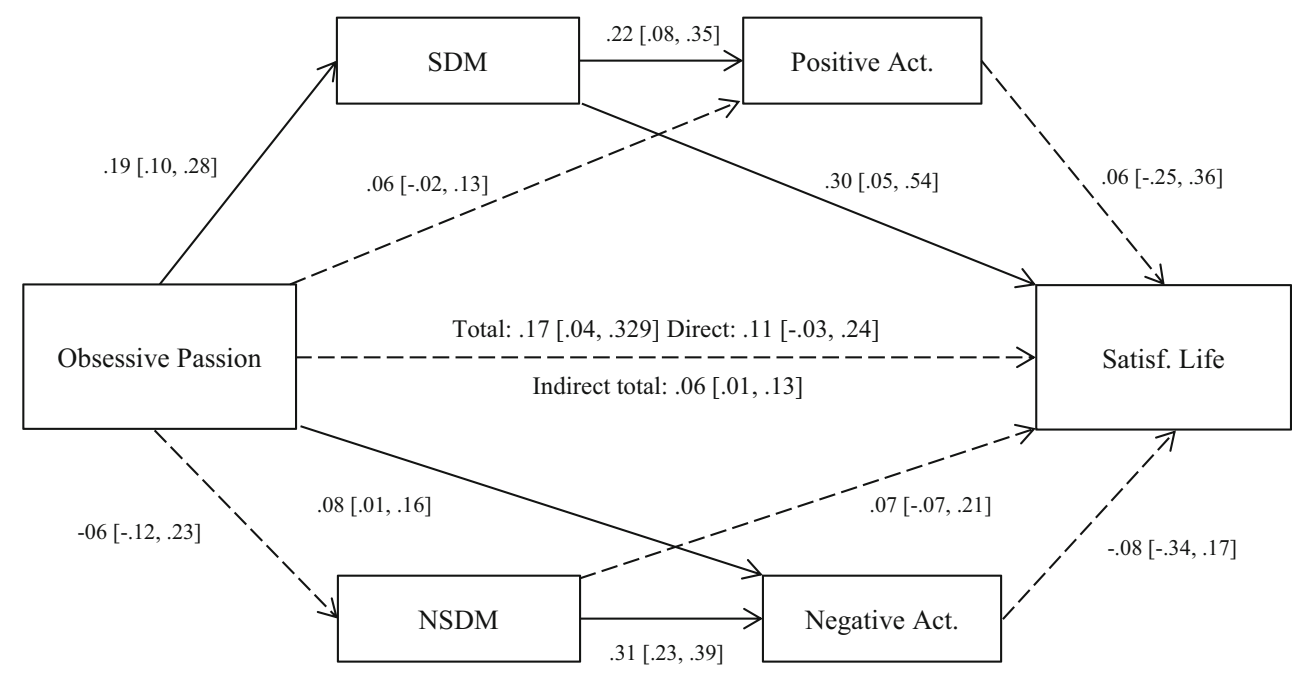

activation, and satisfaction with life. We therefore extend the existing literature of the DMP framework by providing evidence of the distinctiveness between HP and OP as cooccurring constructs in adapted sports.

The correlational analysis made in this study supports a clear and well-known association between the proposed variables in the general population (e.g., physical activity settings; non-adapted sport practice) proposed by several studies (Vallerand et al., 2003; Vallerand, 2015). Specifically HP and OP are moderately correlated with each other, presenting significant associations with SDM (Vallerand et al., 2003; Vallerand, 2015). Consistent with past studies (e.g., Vallerand, 2012), both types of passion displayed positive associations wtih SDM, positive activation, and satisfaction with life, albeit slightly favoring the strength of HP associations. Additionally, HP showed a negative association with NSDM. Finally, positive activation presented a positive and significant relationship with satisfaction with life.

These results represent a general trend for the interaction of these constructs in various sport and exercise settings (Reis et al., 2000; Ryan \& Deci, 2017; Teixeira et al., 2018). However, the results obtained in the correlation analysis showed some distinct patterns regarding the possible association of both types of passion and motivational processes, which may be specific to athletes engaging in adapted sport.

In-depth understanding of the relationships across variables and the development of serial mediation analysis provided crucial results. As reported, the two tested forms of passion did not present significant direct effects on satisfaction with life. However, mediation models presented some significant indirect effects than can be accountable for some motivational spillover. First, the HP model displayed a significant effect with $\operatorname{SDM}(\beta=.42[.25, .59])$ and NSDM $(\beta=-.59[-.92$, $-.26]$ ), and OP model presented significant effects with $\operatorname{SDM}(\beta=.19[.10, .28])$, but not with NSMD. These differentiated results are particularly relevant, as individuals that tend to regulate their behavior in a more self-determined manner also display better cognitive, affective, and behavioral outcomes in the sport context (Ntoumanis et al., 2020; Ryan \& Deci, 2017). In the current sample, athletes with disabilities experience both types of passion, but with a more pronounced expression of HP (Table 1). As stated by several authors, harmonious passion, rooted in autonomous forms of internalization, seems to show a positive association with SDM. Regarding obsessive passion, grounded in controlled forms of internalization, should present weaker or absent relations with SDM. The more controlled types of motivation, for instance, amotivation that represents the lack of intention, or external regulation that may represent an external push to enact the behavior, are therefore expected to not be related to any type of passion, or to be poorly related (Banack et al., 2011; Parastatidou et al., 2014; Vallerand, 1997; Vallerand et al., 2003). The present results sustain previous assumptions and explain the role that an individually relevant activity expressed in an autonomous way and congruent with the self may have in behavioral regulation.

Thus, it seems that both types of passion may contribute to better adaptive behavioral regulation, and with a more pronounced effect of HP in these relations. Firstly, these findings align with the conclusions drawn by Vallerand et al. (2003) regarding a distinct contribution of these types of passion to motivational regulation, favoring the more flexible and pronounced effect of HP in positive outcomes.

Secondly, mediation models also indicated differences between both types of passion on affective activation. The HP exhibited a significant positive effect on positive activation, and the OP a positive effect with negative activation. Additionally, in both mediation models, both SDM and NSDM presented positive relations on positive and negative activation, respectively. Thus, the results tend to support the conceptualization of the influence of passion and motivational determinants on emotional outcomes as proposed by several 
authors (e.g., Salama-Younes, 2018; Teixeira et al., 2018; Vallerand et al., 2007; Vallerand, 2015). Empirically, this allows for a greater differentiation in our understanding of each passion type on well-being indicators.

Thirdly, in terms of subjective well-being, conceptualized within cognitive (e.g., life satisfaction) and affective (e.g., affective activation) dimensions (Diener et al., 1985; Pavot \& Diener, 2008), current results tend to demonstrate a contribution of HP to subjective well-being, both directly (i.e., affective dimension) and indirectly (i.e., cognitive dimension). However, the role of $\mathrm{OP}$ is not as clear, for it presented not only a positive indirect contribution to positive activation through SDM, but also a direct and deleterious effect on the negative activation. Similar findings were reported by Salama-Younes (2018) in a path analysis considering a sample of French older adult runners, showing that HP was a positive predictor of vitality and life satisfaction, the latter being partially mediated by vitality. Additionally, the author found that OP was not a predictor of vitality and had a negative effect on life satisfaction, corroborating several authors and the DMP assumptions of positive outcomes from both types of passion, yet with differentiated effects in well/ill-being outcomes (Parastatidou et al., 2014; Vallerand, 2012, 2015).

Given the hypothesized models proposed in this study and the aformentioned results, several theoretical and practical implications may be presented. On one hand, support for the theoretical model proposed (passion $>$ behavioral regulations $>$ subjective wellbeing) emerged, showing some differentiated associations of the DMP to motivational quality and well-being, favoring the importance of harmonious passion in athletes practice. On the other hand, several indirect effects (motivational spillover) reflect multiple possibilities and relevant factors related with the affective and cognitive aspects of well-being, highlighting the role of harmonious passion and self-determined motivation.

Altogether, and when taking current evidence on the topic, some practical implications may emerge. First, it is important that coaches and caregivers understand that the adapted sports athletes may be prone to developing their activity under the influence of different types of passion, and that the identification of that aspect may be relevant for the athletes persistence, health and well-being. Second, and considering the multidimensional nature of subjective well-being, the sport practice may be one relevant and positive factor for life satisfaction, a wide construct that derives from multiple contextual possibilities, sometimes limited in these athletes daily routine Therefore, providng more incentives and better conditions and solutions for the activity development should be a concern.

\section{Limitations and Future Research}

This study makes a crucial contribution to the existing literature by providing an insight into the combined association between HP and OP and satisfaction with life. However, despite the strengths of previous analysis and results, some limitations should be acknowledged, and further research is needed to account for some of these issues. Firstly, this study has a considerable sample size, taking into account the small overall number of athletes that practice sports at this level of competition. However, the cross-sectional nature of the study highlights the need for experimental studies that may allow a deeper understanding of the predictive power between both types of passion and outcomes variables. On another note, the athletes were all grouped into a large sample, without contemplating the distinctiveness of the modality enrolled, as for the degree of disability presented. Future research may need to address this limitation by relying on sport-specific modalities with the realm of adapted sport. Moreover, sociodemographic characteristics that may have influenced the results of the present study were not accounted for, such as state/national funds to support sport practice, social security support for sport-specific necessities, availability, adequacy and proximity of training and competition sites. These, as for the perceptions of coaches and other possible caregivers, may be particularly useful in order to better understand what goes on in the daily life of athletes with mental or physical disability.

Another aspect that should gather future research attention relates to the scale version used to assess Passion. In the present study, the Portuguese scale version used was based in the proposal made by Vallerand et al. (2003). However, Marsh et al. (2013) have provided evidence for a scale update. To the best of our knowledge, no translation and psychometric testing was made in the Portuguese language considering the updated scale, and future endeavors should be made to assess scale suitability in passion measurement in the Portuguese context.

An additional insight that may warrant some attention in future studies concerns the timing of application of the PS scale. As seen in Bélanger et al. (2013), Mageau et al. (2011) and Verner-Filion et al. (2018), passion (particularly obsessive passion) may be associated with self-worth contingencies and emotional reactions of success/failure. In the present sample $12 \%$ of athletes were approached $1 \mathrm{~h}$ after competition events. This, as suggested by previous authors, may lead to some changes in passion representations, and more research is needed to determine the optimal time delay in this particular setting.

As for motivational variables analyzed, it may be useful to test the models and evaluate the distinctiveness of each variable. The role of each behavioral regulation can be relevant to understand the interactions between variables, as proposed by SDT framework. Additionally, in similar models and 
following some of the previous research, other relevant motivational variables, as is the case for basic psychological needs, may be particularly relevant for a more thorough understanding of variables relation. For that matter, future efforts should be put into the analysis and interpretation of the possible interaction between passion, needs satisfaction, behavioral regulation, and emotional outcomes, and enrich the adapted sport athletes and context understanding.

\section{Conclusion}

The present study shows that marked increases in HP are related to higher levels of autonomous forms of motivation, associated with higher levels of positive activation and thus, greater satisfaction with life. However, HP only had significance when accounting for the indirect effect of SDM and positive affect. These findings have important implications for those who are interested in increasing and/or developing patterns of sport persistence within the adapted sport context. Therefore, those seeking to increase positive outcomes in athletes with disabilities may need to devote great attention to the motivational processes and emotional consequences of sport participation.

Current results provide prospective opportunities for future interventions that will help develop our conceptual and practical understanding of passion and its implications for positive outcomes. In sum, the emergence of distinct passion profiles in athletes with disabilities supports the suggestion that HP and $\mathrm{OP}$ have different implications on motivational processes and affective and cognitive outcomes such as satisfaction with life. Consequently, this concurrent view of harmonious and obsessive passion concerning sport participation provides a more nuanced understanding of athletes' optimal and maladaptive functioning. Current study emphasized the crucial importance of passion experience in greater detail, and also its influential effect on motivational determinants, affective activation, and subjective well-being in athletes with disabilities.

Data Availability The datasets generated during and/or analyzed during the current study are available from the corresponding author on reasonable request.

\section{Declarations}

Ethical Approval All procedures performed in studies involving human participants were in accordance with the ethical standards of the institutional and/or national research committee and with the 1964 Helsinki declaration and its later amendments or comparable ethical standards.

Informed Consent Informed consent was obtained from all individual participants included in the study.
Conflict of Interest Diogo S. Teixeira, Filipe Rodrigues, Anabela Vitorino, Luís Cid, Teresa Bento, Anastasiia Evmenenko, Rita Macedo, Verónica Morales-Sánchez, e Diogo Monteiro declare that they have no conflict of interest.

\section{References}

Allison, P. (2000). Multiple imputation for missing data: A cautionary tale. Sociological Methods \& Research, 28, 301-309. https://doi. org/10.1177/0049124100028003003

Banack, H. R., Sabiston, C., \& Bloom, G. A. (2011). Coach autonomy support, basic need satisfaction, and intrinsic motivation of Paralympic athletes. Research Quarterly for Exercise and Sport, $84,722-730$. h t tp s://doi .org/10.5641/ $027013611 X 13275192111989$

Balaguer, I., Castillo, I., \& Duda, J. L. (2008). Apoyo a la autonomía, satisfacción de las necesidades, motivación y bienestar en deportistas de competición: Un análisis de la teoría de la autodeterminación [Autonomy support, needs satisfaction, motivation and well-being in competitive athletes: a test of the selfdetermination theory]. Revista de Psicología del Deporte, 17(1), 123-139

Bartholomew, K. J., Ntoumanis, N., Ryan, R. M., \& ThøgersenNtoumani, C. (2011). Psychological need thwarting in the sport context: Assessing the darker side of athletic experience. Journal of Sport and Exercise Psychology, 33, 75-102.

Bélanger, J. J., Lafrenière, M.-A. K., Vallerand, R. J., \& Kruglanski, A. W. (2013). Driven by fear: The effect of success and failure information on passionate individuals' performance. Journal of Personality and Social Psychology, 104, 180-195. https://doi.org/ 10.1037/a0029585

Busseri, M., \& Sadava, S. (2010). A review of the tripartite structure of subjective well-being: Implications for conceptualization, operationalization, analysis, and synthesis. Personality and Social Psychology Review, 15, 290-314. https://doi.org/10.1177/ 1088868310391271

Carpentier, J., \& Mageau, G. A. (2013). When change-oriented feedback enhances motivation, well-being and performance: A look at autonomy-supportive feedback in sport. Psychology of Sport and Exercise, 14(3), 423-435. https://doi.org/10.1016/j.psychsport. 2013.01.003

Cid, L., Vitorino, A., Bento, T., Teixeira, D. S., Rodrigues, F., \& Monteiro, D. (2019). The passion scale-Portuguese version: Reliability, validity, and invariance of gender and sport. Perceptual and Motor Skills, 126, 1-19. https://doi.org/10.1177/ 0031512519849744

Curran, T., Appleton, P., Hill, A., \& Hall, H. (2013). The mediating role of psychological need satisfaction in relationships between types of passion for sport and athlete burnout. Journal of Sport Sciences, 31, 597-606. https://doi.org/10.1080/02640414.2012.742956

Curran, T., Hill, A. P., Appleton, P. R., Vallerand, R. J., \& Standage, M. (2015). The psychology of passion: A meta-analytical review of a decade of research on intrapersonal outcomes. Motivation and Emotion, 39, 631-655. https://doi.org/10.1007/s11031-015-9503-0

Diener, E. (1984). Subjective well-being. Psychological bulletin, 95. Available at SSRN: https://ssrn.com/abstract=2162125, 95, 542, 575

Diener, E. (1985). The Satisfaction with life scale. Journal of Personality Assessment, 49, 71-75. https://doi.org/10.1207/s15327752jpa4901_13

Diener, E. (1994). Assessing subjective well-being: Progress and opportunities. Social Indicators Research, 31, 103-157. https://doi.org/ 10.1007/BF01207052 
Diener, E., Emmons, R. A., Larsen, R. J., \& Griffin, S. (1985). The Satisfaction with life scale. Journal of Personality Assessment, 49, 71-75. https://doi.org/10.1207/s15327752jpa4901_13

Deci, E. L., \& Ryan, R. M. (1985). Intrinsic motivation and selfdetermination in human behavior. Plenum.

Deci, E., \& Ryan, R. (2000). The "what" and "why" of goal pursuits: Human needs and the self determination of behavior. Psychological Inquiry, 11, 227-268. https://doi.org/10.1207/S15327965PLI1104_ 01

DePauw, K., \& Gavron, S. (2005). Disability sport (2nd ed.). Champaign, IL.

Ekkekakis, P. (2013). The measurement of affect, mood and emotion. University Press.

Feldman Barrett, L., \& Russell, J. A. (1998). Independence and bipolarity in the structure of current affect. Journal of Personality and Social Psychology, 74(4), 967-984. https://doi.org/10.1037/0022-3514.74. 4.967

Felton, L., \& Jowett, S. (2013). "what do coaches do" and "how do they relate": Their effects on athletes' psychological needs and functioning. Scandinavian Journal of Medicine \& Science in Sports, 23, e130-e139. https://doi.org/10.1111/sms.12029

Forrest, J., Mageau, G., Sarrazin, C., \& Morin, E. (2011). "Work is my passion": The different affective, Behavioural, and cognitive consequences of harmonious and obsessive passion toward work. Canadian Journal of Administrative Sciences, 28, 27-40.

Gagné, M., \& Blanchard, C. (2007). Self-determination theory and wellbeing in athletes: It's the situation that counts. In M. S. Hagger \& N. L. D. Chatzisarantis (Eds.), Intrinsic motivation and selfdetermination in exercise and sport (pp. 243-254,353-355). Human Kinetics.

Galinha, I., Pereira, C., \& Esteves, F. (2014). Short-form of the Portuguese version of the positive and negative affect schedule PANAS-port-VRP: Confirmatory factorial analysis and temporal invariance. Psicologia, 28(1), 53-65.

Gillet, N., Vallerand, R. J., Lafrenière, M.-A. K., \& Bureau, J. S. (2013). The mediating role of positive and negative affect in the situational motivation-performance relationship. Motivation and Emotion, 37, 465-479. https://doi.org/10.1007/s11031-012-9314-5

Hair, J., Babin, B. J., Anderson, R. E., \& Black, W. C. (2019). Multivariate Data Analysis (8th ed.). Hoboken, NJ.

Hayes, A. (2018). Introduction to mediation, moderation, and conditional process analysis. A regression-based approach (2nd ed.). The Guilford Press.

Heo, J., Lee, Y., Lundberg, N., McCormick, B., \& Chun, S. (2008). Adaptive sport as serious leisure: Do self-determination, skill level, and leisure constraints matter? Annual in Therapeutic Recreation, $16,31-38$.

Hodgins, H. S., \& Knee, C. R. (2002). The integrating self and conscious experience. In E. L. Deci \& R. M. Ryan (Eds.), Handbook of selfdetermination research (p. 87-100). University of Rochester Press: Rochester.

Houlfort, N., Fernet, C., Vallerand, R., Laframboise, A., Guay, F., \& Koestner, R. (2015). The role of passion for work and need satisfaction in psychological adjustment to retirement. Journal of Vocational Behavior, 88, 84-94.

IPC (2015). Strategic plan 2015 to 2018 - strategic outlook for the international Paralympic committee. Disponível em International Paralympic Committee.

Jowett, S., Adie, J., Bartholomew, K., Yang, S., Gustafsson, H., \& LópezJiménez, H. (2017). Motivational processes in the coach-athlete relationship: A multi-cultural self-determination approach. Psychology of Sport and Exercise, 32, 143-152. https://doi.org/10. 1016/j.psychsport.2017.06.004

Kent, S., Kingston, K., \& Paradis, K. (2018). The relationship between passion, Basic Psychological Needs Satisfaction and Athlete Burnout: Examining Direct and Indirect Effects. Journal of
Clinical Sport Psychology, 12, 75-96. https://doi.org/10.1123/jcsp. 2017-0030

Lalande, D. R., Vallerand, R. J., Lafrenière, M.-A. K., Verner-Filion, J., Laurent, F.-A., Forest, J., \& Paquet, Y. (2017). Obsessive passion: A compensatory response to unsatisfied needs. Journal of Personality, 85, 163-178. https://doi.org/10.1111/jopy.12229

Lightheart, V. L., Wilson, P. M., \& Oster, K. (2010). Strength versus balance: The contributions of two different models of psychological need satisfaction to well-being in adapted sport athletes. In I. E. Wells (Ed.), Psychological well-being (pp. 157-170). Nova Science.

Lundberg, N., Groff, D., \& Zabriskie, R. (2010). Psychological need Satisfaction through sports participation among international athletes with cerebral palsy. Annals of Leisure Research, 13, 102115. https://doi.org/10.1080/11745398.2010.9686840

Macdougall, H., O'Halloran, P., Sherry, E., \& Shields, N. (2015). Needs and strengths of Australian Para athletes: Identifying their subjective, psychological, social, and physical health and well-being. Sport Psychologist, 30, 1-12. https://doi.org/10.1123/tsp.2015-0006

Mageau, G. A., Carpentier, J., \& Vallerand, R. J. (2011). The role of selfesteem contingencies the distinction between obsessive and harmonious passion. European Journal of Social Psychology, 41, 720 729. https://doi.org/10.1002/ejsp.798

Martin, J. (2018). Handbook of Disability Sport \& Exercise Psychology. Oxford University Press.

Monteiro, D., Marinho, D. A., Moutão, J., Couto, N., Antunes, \& Cid, L. (2016). Adaptation and Validation of Basic Psychological Needs Exercise Scale to the sport domain and invariance across soccer and swimming. Motricidade, 12(4), 51-61. https://doi.org/10. 6063/motricidade.9372

Monteiro, D., Pelletier, L., Moutão, J., \& Cid, L. (2018). Examining the motivational determinants of enjoyment and the intention to continue of persistence competitive swimmers. International Journal of Sport Psychology, 49, 1-00. https://doi.org/10.7352/IJSP.2018.49

Monteiro, D., Teixeira, D. S., Travassos, B., Duarte-Mendes, P., Machado, S., Moutão, J., \& Cid, L. (2018b). Perceived effort in football athletes: The role of achievement goal theory and selfdetermination theory. Frontiers in Psychology, 9(1575), 1-13. https://doi.org/10.3389/fpsyg.2018.01575

Monteiro, D., Teixeira, D. S., Vitorino, A., Moutão, J., Rodrigues, F., Machado, S., \& Cid, L. (2019). Behavioral regulation sport questionnaire (BRSQ): Gender and sport invariance in Portuguese athletes. Perceptual and Motor Skills, 126, 1-19. https://doi.org/10. $1177 / 0031512519825700$

Neto, F. (1993). Satisfaction with life scale: Psychometric properties in an adolescent sample. Journal of Youth and Adolescence, 22(2), 125134.

Ntoumanis, N., Ng, J. Y. Y., Prestwich, A., Quested, E., Hancox, J. E., Thogersen-Ntoumani, C., et al. (2020). Meta-analysis of selfdetermination theory-informed intervention studies in the health Domain: Effects on Motivation, Health Behavior, Physical, and Psychological Health. Health Psychology Review. https://doi.org/ 10.1080/17437199.2020.1718529

Nunez, J., León, J., González, V., \& Martín-Albo, J. (2011). Propuesta de un modelo explicativo del bienestar psicológico en el contexto Deportivo. Revista de Psicología del Deporte, 20, 223-242.

Parastatidou, I. S., Doganis, G., Theodorakis, Y., \& Vlachopoulos, S. P. (2014). The mediating role of passion in the relationship of exercise motivational regulations with exercise dependence symptoms. International Journal of Mental Health and Addiction, 12, 406419. https://doi.org/10.1007/s11469-013-9466-x

Pavot, W., \& Diener, E. (2008). The Satisfaction with life scale and the emerging construct of life satisfaction. The Journal of Positive Psychology, 3(2), 137-152. https://doi.org/10.1080/ 17439760701756946 
Pelletier, L., \& Sarrazin, P. (2007). Measurement issues in selfdetermination theory and sport. In M. Hagger \& N. Chatzisarantis (Eds.), Intrinsic motivation and self-determination in exercise and sport (pp. 143-152). Champaing-Illinois.

Perreault, S., \& Vallarand, R. J. (2007). A test of self-determination theory with wheelchair basketball players with and without disability. Adapted physical activity quarterly: APAQ, 24(4), 305-316.

Preacher, K. J., \& Hayes, A. F. (2008). Asymptotic and resampling strategies for assessing and comparing indirect effects in multiple mediator models. Behavior Research Met, 40, 879-891.

Reis, H., Sheldon, K., Gable, S., Roscoe, R., \& Ryan, R. (2000). Daily well-being: The role of autonomy, competence, and relatedness. Personality and Social Psychology Bulletin, 26(4), 419-435. https://doi.org/10.1177/0146167200266002

Rip, B., Fortin, S., \& Vallerand, R. J. (2006). The relationship between passion and injury in dance students. Journal of Dance, Medicine \& Science, 10, 14-20.

Rodrigues, F., Teixeira, D. S., Neiva, H., Cid, L., \& Monteiro, D. (2020). The bright and dark sides of motivation as predictors of enjoyment, intention, and exercise persistence. Scandinavian Journal of Medicine \& Science in Sports, 30, 1-14. https://doi.org/10.1111/ sms. 13617

Ryan, R., \& Deci, E. (2017). Self-determination theory. In Basic psychological needs in motivation, development and wellness. The Guilford Press.

Salama-Younes, M. (2018). Passion types and subjective well-being for French older adult runners. Journal of Leisure Research, 49, 1-19. https://doi.org/10.1080/00222216.2018.1505160

Sarrazin, P., Boiché, J., \& Pelletier, L. (2007). "A self-determination theory approach to dropout in athletes," in Intrinsic Motivation and Self-Determination in Exercise and Sport, eds M. Hagger and N. Chatzisarantis (Illinois: Human Kinetics), 229-241.

Seaward, B. (2000). Stress and human spirituality 2000: At the crossroads of physics and metaphysics. Applied Psychophysiology and Biofeedback, 25(4), 241-246.

Schiphof-Godart, L., \& Hettinga, F. J. (2017). Passion and pacing in endurance performance. Frontiers in Physiology, 8. https://doi.org/ $10.3389 /$ fphys.2017.00083

Shrout, P., \& Bolger, N. (2002). Mediation in experimental and nonexperimental studies: New procedures and recommendations. Psychological Methods, 7, 422-445.

Teixeira, D. S., Marques, M. M., \& Palmeira, A. L. (2018). Associations between affect, basic psychological needs and motivation in physical activity contexts: Systematic review and meta-analysis. Revista Iberoamericana de Psicologia del Ejercicio y el Deporte, 13, 225233.

Teixeira, D. S., Silva, M. N., \& Palmeira, A. L. (2018). How does frustration make you feel? A motivational analysis in exercise context. Motivation and Emotion, 42, 1-10. https://doi.org/10.1007/s11031018-9690-6

Teixeira, D. S., Pelletier, L., Monteiro, D., Rodrigues, F., Moutão, J., Marinho, D., \& Cid, L. (2019). Motivational patterns in persistent swimmers: A serial mediation analysis. European Journal of Sport Sciences., 20, 660-669. https://doi.org/10.1080/17461391.2019. 1675768

Vallerand, R. J. (1997). Toward a hierarchical model of intrinsic and extrinsic motivation. In M. P. Zanna (Ed.), Advances in experimental social psychology (pp. 271-360). San Diego: Academic Press.

Vallerand, R. J. (2012). From motivation to passion: In search of the motivational processes involved in a meaningful life. Canadian Psychology, 53(1), 42-52. https://doi.org/10.1037/a0026377

Vallerand, R. J. (2015). The psychology of passion: A dualistic model. (R. J. Vallerand, Ed.). Oxford University press.

Vallerand, R. J., Mageau, G. A., Elliot, A. J., Dumais, A., Demers, M. A., \& Rousseau, F. (2008). Passion and performance attainment in sport. Psychology of Sport and Exercise, 9(3), 373-392. https:// doi.org/10.1016/j.psychsport.2007.05.003

Vallerand, R. J., Mageau, G. A., Ratelle, C., Léonard, M., Blanchard, C., Koestner, R., et al. (2003). Les passions de 1'Âme: On obsessive and harmonious passion. Journal of Personality and Social Psychology, 85(4), 756-767. https://doi.org/10.1037/0022-3514.85.4.756

Vallerand, R. J., Rousseau, F., Grouzet, F., Dumais, A., Grenier, S., \& Blanchard, C. (2006). Passion in sport: A look at determinants and affective experiences. Journal of Sport \& Exercise Psychology, 28, 454-478

Vallerand, R. J., Salvy, S. J., Mageau, G. A., Elliot, A. J., Denis, P. L., Grouzet, F. M. E., \& Blanchard, C. (2007). On the role of passion in performance. Journal of Personality, 75(3), 505-534. https://doi. org/10.1111/j.1467-6494.2007.00447.x

Vallerand, R., \& Verner-Filion, J. (2020). Theroy and research in passion for sport and exercise. In G. Tenenbaum \& R. Eklund (Eds.), Handbook of sport psychology (pp. 206-230). Wiley.

Verner-Filion, J., Schellenberg, B. J. I., Rapaport, M., Bélanger, J. J., \& Vallerand, R. J. (2018). "The Thrill of Victory... and the Agony of Defeat": Passion and Emotional Reactions to Success and Failure among Recreational Golfers. Journal of Sport and Exercise Psychology, 40, 280-283. https://doi.org/10.1123/jsep.2017-0316

Warburton, V. E., Wang, J. C. K., Bartholomew, K. J., Tuff, R., \& Bishop, K. (2020). Need satisfaction and need frustration as distinct and potentially co-occurring constructs: Need profiles examined in physical education and sport. Motivation and Emotion, 44, 54-66. https://doi.org/10.1007/s11031-019-09798-2

Watson, D., Clark, L. A., \& Tellegen, A. (1988). Development and validation of brief measures of positive and negative affect: The PANAS scales. Journal of Personality and Social Psychology, 47, 1063-1070.

Watson, D., Wises, D., Vaidya, J., \& Tellegen, A. (1999). The two general activation systems of affect: Structural findings, evolutionary considerations, and psychological evidence. Journal of Personality and Social Psychology, 76, 820-838.

Publisher's Note Springer Nature remains neutral with regard to jurisdictional claims in published maps and institutional affiliations. 